\title{
La política internacional de la regulación del cannabis en Uruguay. Un análisis de la respuesta uruguaya a los desafíos y oportunidades del régimen internacional de drogas
}

\author{
Nicolás ÁlVAREZ* \\ Nicolás Pose ${ }^{* *}$ \\ CARLOS LujáN ${ }^{* * *}$
}

Artículo recibido: 13 de octubre de 2016

Artículo aprobado: 18 de abril de 2017

Doi: http://dx.doi.org/10.12804/revistas.urosario.edu.co/desafios/a.5223

Para citar este artículo: Álvarez, N., Pose, N., \& Luján, C. (2017). La política internacional de la regulación del cannabis en Uruguay. Un análisis de la respuesta uruguaya a los desafíos y oportunidades del régimen internacional de drogas. Desafios, 29(2). 19-59. doi: http:// dx.doi.org/10.12804/revistas.urosario.edu.co/desafios/a.5223

\footnotetext{
* Estudiante de la Maestría en Ciencia Política, Universidad de la República, Uruguay. Licenciado en Ciencia Política por la Universidad de la República, Uruguay y Especialista en Seguridad Internacional por la Universidad Santiago de Compostela, España. Correo electrónico: nicolasalvarezrosas@gmail.com. ORCID: http://orcid.org/0000-0002-3988-2202 ** Estudiante del MSc in International Political Economy, London School of Economics and Political Science, Reino Unido. Becario Chevening. Licenciado en Ciencia Política y diplomado en Estudios Internacionales por la Universidad de la República, Uruguay. Profesor ayudante del Instituto de Ciencia Política e Investigador asociado al Programa de Estudios Internacionales, ambos de la Universidad de la República, Uruguay. Correo electrónico: n.pose@1se.ac.uk. ORCID: http://orcid.org/0000-0002-4462-1189

*** Doctor en Ciencias Humanas por la Universidad Católica de Uruguay. Docente del Instituto de Ciencia Política de la Universidad de la República, Uruguay. Correo electrónico: clujan62@hotmail.com. ORCID: http://orcid.org/0000-0002-4742-6696
} 


\title{
Resumen
}

Este artículo analiza la estrategia uruguaya de regulación del cannabis en el ámbito internacional. Cuatro son las preguntas abordadas a lo largo del trabajo: (i) ¿Cómo un pequeño país logró modificar su politica hacia el cannabis en un contexto internacional a priori hostil a las innovaciones? (ii) ¿Cómo logró sortear los obstáculos políticos y legales? (iii) ¿Cuáles fueron las consecuencias para Uruguay en términos internacionales? ¿Y (iv) las consecuencias para otros países y para el régimen internacional de combate a las drogas? Tras la identificación de tres etapas distintivas de la estrategia, influenciadas porfactores tanto exógenos como endógenos, se afirma que una ventana de oportunidad, capitalizada por los representantes del Estado uruguayo, permitio al gobierno asegurar un espacio de autonomía en la esfera internacional que posibilitó la implementación de la política deseada.

Palabras clave: regulación del cannabis, régimen internacional de drogas, autonomía, politica internacional, Uruguay

\section{The International Politics of Cannabis Regulation in Uruguay. An Analysis of the Uruguayan Response to the Challenges and Opportunities from the International Drugs Regime}

\begin{abstract}
This article analyses the international strategy followed by the government of Uruguay with regard to its policy of cannabis regulation. It seeks to answer four questions: (i) How did a small country like Uruguay manage to change its policy in an international environment a priori hostile to innovations? (ii) How did it manage to avoid the legal and political obstacles it faced? (iii) Which were the consequences for Uruguay in international terms? And (iv) which were the consequences for other countries and for the international drugs regime? After identifying three stages of the strategy, influenced by both exogenous and endogenous factors, we assert that a window opportunity, capitalized by state officials, allowed the government to secure the necessary degree of autonomy from the international stage to implement its desired policy. Keywords: Cannabis regulation, international drugs regime, autonomy, international politics, Uruguay
\end{abstract}




\title{
A política internacional da regulação do cannabis no Uruguai. Uma análise da resposta uruguaia aos desafios e oportunidades do regime internacional de drogas
}

\begin{abstract}
Resumo
Este artigo analisa a estratégia uruguaia de regulação do cannabis no âmbito internacional. Quatro são as perguntas abordadas ao longo do trabalho: (i) como um pequeno país conseguiu modificar a sua politica do Cannabis em um contexto internacional a priori hostil às inovações? (ii) Como conseguiu sortear os obstáculos políticos e legais? (iii) Quais foram as consequências para o Uruguai em termos internacionais? E (iv) as consequências para outros países e para o regime internacional de combate de drogas? Após a identificação de três etapas distintivas da estratégia, influenciadas por fatores tanto exógenos como endógenos, afirma-se que uma janela de oportunidade, capitalizada pelos representantes do Estado uruguaio, permitiu ao governo assegurar um espaço de autonomia a esfera internacional que possibilitou a implementação da política desejada. Os dados utilizados para a construção dos nossos argumentos provêm de duas pesquisas prévias que temos levado a cabo desde o Instituto de Ciência Política da Universidade da República durantes os anos 2015 e 2016.
\end{abstract}

Palavras-chave: regulação do cannabis, regime internacional de drogas, autonomia, política internacional, Uruguai

\section{Introducción}

Luego de un año de discusión en el Parlamento, en mayo del año 2014, el Poder Ejecutivo uruguayo reglamentó la Ley No 19172 sobre el control y regulación del cannabis y sus derivados. Producto de los cuestionamientos recibidos desde el ámbito internacional, el gobierno implementó una estrategia dirigida a justificar la iniciativa, generar aliados y contener las críticas provenientes desde el exterior. Este trabajo aborda las siguientes preguntas: ¿cómo un pequeño país logró modificar su política hacia el cannabis en un contexto internacional a priori hostil a las innovaciones? ¿Cómo logró sortear los obstáculos políticos y legales? ¿Cuáles fueron las consecuencias para Uruguay 
en términos internacionales? ¿Y las consecuencias para otros países y para el régimen internacional de combate a las drogas?

Procurando dar una respuesta, se analiza la estructura del régimen internacional de drogas y el posicionamiento de sus principales actores, las amenazas surgidas tras la presentación de la iniciativa, la búsqueda de aliados a nivel internacional (estados nacionales, organismos intergubernamentales y organizaciones no gubernamentales) y el vínculo de la política doméstica con el plano de la negociación internacional. Los datos utilizados provienen de dos investigaciones anteriores llevadas a cabo por los autores desde el Instituto de Ciencia Política de la Universidad de la República durante los años 2015 y $2016^{1}$.

Tras la identificación de tres etapas distintivas, influenciadas por factores tanto exógenos como endógenos, se afirma que una ventana de oportunidad, capitalizada por los representantes del Estado uruguayo, permitió al gobierno asegurar un espacio de autonomía en la esfera internacional que posibilitó la implementación de la política deseada. Y, lo que es más, que finalmente la innovación no solo no supuso un costo reputacional para el país, sino que además le permitió cosechar réditos políticos y de imagen previamente impensados. Asimismo, se proyecta que la iniciativa no provocará una disrupción de magnitud en el régimen internacional de combate a las drogas en el corto plazo. Pero que, no obstante, mediante la ampliación de las opciones de política socialmente consideradas como posibles y aceptables, y a través de la reducción de los costos percibidos por innovar en el orden de las relaciones diplomáticas, la propuesta uruguaya facilita el camino a la adopción de nuevas estrategias frente al cannabis en otros países.

El artículo se estructura de la siguiente manera. En primer lugar se presenta el marco teórico-metodológico, y a continuación se analiza el posicionamiento de los principales actores del régimen en el continuo cambio-continuidad con respecto al enfoque hegemónico de drogas. En tercer lugar se desarrolla la estrategia internacional de pre-

\footnotetext{
1 A partir de dos convenios celebrados con la Junta Nacional de Drogas de Presidencia de la República de Uruguay.
} 
sentación y defensa de la política de drogas de Uruguay y se analizan sus resultados. Por último, se exponen las reflexiones finales sobre el impacto de la iniciativa uruguaya en otros países y en el régimen internacional de combate a las drogas.

\section{Marco teórico-metodológico}

\section{Un régimen internacional de combate a las drogas}

Este trabajo asume como punto de partida que la existencia de un conjunto de normas jurídicas de carácter internacional, prácticas usuales seguidas por los Estados y organismos internacionales vinculados con el fenómeno de las sustancias psicoactivas de carácter ilegal —comúnmente referidas como "drogas"- constituye un régimen internacional. De acuerdo a la clásica definición de Stephen Krasner (1982a), un régimen internacional consiste en un conjunto de principios, normas, reglas y procedimientos de toma de decisiones, en torno a los cuales las expectativas de los actores convergen en un tema dado de las relaciones internacionales.

Este régimen, basado en la extendida creencia de que el consumo de sustancias psicoactivas constituye un fenómeno indeseable y, por ende, a erradicar, se cimenta sobre tres convenciones internacionales (1961 —enmendada en 1972 — 1971 y 1988) que regulan el comportamiento de los Estados nacionales sobre el tema. Los tres órganos centrales son la Comisión de Estupefacientes, ámbito de toma de decisiones intergubernamental incrustado en el sistema de las Naciones Unidas (ONU); la Oficina de las Naciones Unidas contra la Droga y el Delito (UNODC, por sus siglas en inglés) y la Junta Internacional de Fiscalización de Estupefacientes (JIFE), cuerpo técnico encargado de la supervisión del cumplimiento de las convenciones. A su vez, por su rol de asesor de la Comisión de Estupefacientes para la elaboración de las listas de sustancias psicoactivas prohibidas, la Organización Mundial de la Salud (OMC), mediante su Comité de Expertos, ejerce un papel relevante. 
Los motivos por los cuales los Estados aceptan restringir su espacio para la acción mediante la creación y la adhesión a regímenes internacionales han sido uno de los principales temas de debate en el campo de las relaciones internacionales. La búsqueda de Estados poderosos de alcanzar sus intereses mediante estos arreglos (Krasner, 1982b), el objetivo de solucionar problemas de acción colectiva (Stein, 1982), o de reducir los costos de transacción (Keohane, 1982), han sido algunos argumentos mencionadas por la literatura. Una de las explicaciones más difundidas viene dada por la teoría de la estabilidad hegemónica que sostiene que, en un mundo internacional anárquico, los regímenes requieren de un Estado líder (hegemónico) o de un grupo de Estados líder que los conduzcan y ejerzan como los garantes del cumplimiento de sus disposiciones (Kindleberger, 1981; Gilpin, 1987).

De acuerdo a Krasner (1982b), una vez consolidados los regímenes adquieren vida propia e incluso la fuerza de la inercia los mantiene en pie cuando han cambiado los intereses de los actores que los crearon. Además, si los argumentos de la teoría de la política burocrática (Peters, 1999) son extrapolables a la realidad internacional, se espera que las acciones de los funcionarios internacionales de los órganos del régimen ejerzan presión a favor de la continuidad. Finalmente, en un orden internacional caracterizado por una creciente - aunque paulatina, y asimétrica entre áreas - desconcentración del poder, con Estados con posiciones conservadoras en materia de drogas que aspiran a un estatus de potencia mundial (China), o al menos a recobrar un mayor perfil internacional (Rusia), el régimen de combate a las drogas no parece tan amenazado — a pesar del cambio de posición de Estados Unidos-. En todo caso, su capacidad de ejercer como freno frente a iniciativas reformistas permanece como una cuestión empírica.

\section{Regímenes regionales}

Como en otras arenas, el régimen internacional de drogas convive con múltiples regímenes regionales que implican un constreñimiento adicional a la acción de los Estados. En el caso americano, las acciones iniciales de la Organización de los Estados Americanos (OEA) supusieron una réplica del régimen internacional liderado por Estados 
Unidos. No obstante, con el paso del tiempo y los cambios políticos, los regímenes regionales también adquieren sus propias dinámicas, por lo que su interacción con el régimen internacional y con las opciones de política de los Estados nacionales se vuelve un tema de análisis relevante por derecho propio.

Igualmente, así como el fin de la Guerra Fría supuso el ascenso de las regiones como unidades políticas de relevancia analítica (Hettne y Söderbaum, 2000), desde mediados de la primera década del siglo XXI se observa en América Latina la emergencia de nuevas organizaciones e instituciones sin la participación de Estados Unidos en lo que algunos autores llaman regionalismo posliberal (Sanahuja, 2012; Serbin, 2012). Estas organizaciones, como la Unión de Naciones Suramericanas (UNASUR) o la Comunidad de Estados Latinoamericanos y Caribeños (CELAC), han buscado articular posiciones respecto al tema drogas entre sus miembros, agregando así nuevas voces en el escenario internacional y complejizando el vínculo entre el régimen internacional de drogas, los regímenes regionales y los Estados nacionales.

\section{Estado y vínculo doméstico-internacional}

En este contexto internacional, los Estados diseñan sus estrategias para alcanzar los objetivos políticos que desean. En el caso de Uruguay, con respecto al tema drogas, el gobierno procuró el espacio de autonomía suficiente para implementar una política de regulación del cannabis que chocaba contra la ortodoxia consagrada en el régimen internacional vigente. Sin embargo, como nos enseñan los teóricos de la toma de decisiones en política exterior (Allison, 1971; George, 1991), los gobiernos no son unidades monolíticas, sino que en su interior conviven distintas visiones y racionalidades acerca de cómo encarar los diversos desafíos de política pública. Y además, estos organizan, con el presidente como vértice, distintos esquemas de comunicación e intercambio que tienen consecuencias en la calidad y la celeridad de las políticas, en la eficiencia de los recursos materiales y humanos utilizados, y sobre el grado de consenso que generan. 
En la arena internacional de drogas —una política exterior no tradicional - conviven diferentes agencias con agendas y objetivos no siempre coincidentes. Por ejemplo, en el caso uruguayo, es posible especular con que la Junta Nacional de Drogas (JND) buscara una política más intransigente respecto al aseguramiento del espacio para implementar la iniciativa, mientras que la Cancillería, preocupada por las relaciones internacionales del país en su conjunto, se mostrara más cautelosa.

Pero además, como bien advierte Moravsik (1997; 2008) en su crítica al realismo estructural, para entender las posiciones de los Estados en el escenario internacional es preciso considerar las preferencias de las sociedades en el plano doméstico. Para captar esto, uno de los modelos más adecuados es el ya clásico juego de dos niveles de Robert Putnam (1988). Este autor propone que las negociaciones internacionales pueden entenderse como un juego que se desarrolla en dos planos. En el nivel I o internacional, los gobernantes negocian con sus pares estatales en busca de satisfacer su interpretación del interés nacional. Sin embargo, estos a su vez deben asegurarse de que el resultado alcanzado se corresponda con las preferencias de su base de apoyo en el nivel II o doméstico si esperan que su estrategia internacional sea ratificada internamente. Por lo tanto, ambas mesas están interrelacionadas. Y, además, estas incorporan la posibilidad de interacciones y alianzas transnacionales en las que los gobiernos establecen alianzas con coaliciones políticas y sociales de otros Estados e incluso donde las propias bases domésticas se saltan la mediación de los Estados para entablar alianzas entre sí.

Este modelo, por tanto, implica analizar cómo el gobierno uruguayo procuró un espacio de autonomía en las negociaciones internacionales que satisfaciera a sus bases de apoyo, de cara a asegurar la implementación de la política deseada. Y, al mismo tiempo, supone explorar la posibilidad de alianzas con actores de la sociedad civil internacional. 


\section{Estrategia metodológica}

Para cumplir con los objetivos de este artículo, hemos recurrido al empleo de cuatro técnicas cualitativas de recolección y análisis de datos:

i. análisis documental;

ii. entrevistas abiertas y en profundidad a políticos e informantes calificados;

iii. entrevistas semiestructuradas - por correo electrónico- a representantes diplomáticos de Uruguay en el exterior y a representantes de organizaciones de las sociedad civil internacional;

iv. grupos de discusión con los actores participantes de la política de drogas de Uruguay y con organizaciones políticas y de la sociedad civil.

\section{Análisis documental}

Se utilizaron tres tipos de fuentes: (i) prensa; (ii) documentos técnicos y políticos; y, (iii) artículos y libros de carácter académico. Con respecto al primer tipo de fuente, se cubrió un espacio temporal de tres años (20132015) mediante el archivo de prensa sistematizado por la JND. La recolección se realizó a partir de la construcción de tres categorías analíticas definidas con anterioridad: (i) la relación entre el régimen internacional y los países y regiones; (ii) la relación entre el régimen internacional y los organismos internacionales y regionales; y, (iii) el rol del gobierno uruguayo en la presentación de la política de regulación del cannabis a nivel internacional. En lo que refiere al uso de datos provenientes del ámbito académico y político, se analizaron artículos, documentos elaborados por gobiernos y organizaciones de la sociedad civil y material producido por los sistemas de la OEA y ONU.

\section{Entrevistas en profundidad}

Producto de las evaluaciones mencionadas anteriormente, se contó para la elaboración de este artículo con material recabado mediante la técnica de entrevistas. En particular, en el curso de las mencionadas 
investigaciones, se realizaron un total de treinta y dos entrevistas, dentro de las que se destaca la cobertura de los nueve viceministros integrantes de la JND, el presidente y distintos integrantes del área técnica del Instituto de Regulación y Control del Cannabis de Uruguay, senadores de la República e integrantes del Comité Científico Académico de seguimiento de la regulación del mercado de cannabis. En lo que se refiere a la estructuración de la pauta de las entrevistas correspondientes a la dimensión internacional, se cubrieron tres grandes ejes temáticos: (i) el régimen internacional de combate a las drogas; (ii) el doble rol del gobierno uruguayo en las negociaciones por la política de regulación; y, (iii) los efectos de difusión.

\section{Entrevistas semiestructuradas aplicadas por correo electrónico}

En el marco de las investigaciones reseñadas, y con el apoyo la Cancillería, se envió un set de preguntas a todas las embajadas uruguayas en el exterior. La solicitud se estructuró en función de dos grandes preguntas: (i) pedidos de información a la embajada por parte de los gobiernos, actores políticos y sociales de los respectivos países y (ii) las repercusiones registradas en la prensa en referencia al proceso de regulación del cannabis en Uruguay.

\section{Grupos de discusión}

Al igual que con las entrevistas, la técnica de grupos de discusión fue aplicada en las evaluaciones que anteceden a este artículo. En particular, se desarrollaron siete grupos de discusión. Los primeros cinco se integraron con funcionarios de los ministerios con competencias en el área. Los restantes fueron integrados por representantes de los partidos políticos con representación parlamentaria y por organizaciones de la sociedad civil nacional. Fundamentalmente, se buscó conocer la visión de los participantes de la estrategia internacional del país en el tema en términos de coparticipación en la elaboración, así como identificar posturas de apoyo o rechazo. Y, además, se exploraron los vínculos de los actores nacionales en esta arena con sus pares a nivel internacional. 


\section{El régimen y los actores: cambio-continuidad}

Postulamos que es posible ubicar a los distintos actores que participan o interactúan con el régimen de drogas en un continuo espacial, en donde un polo representa a las interpretaciones más estrictas de las convenciones y el otro a las visiones que promueven una mayor flexibilidad con relación a estas. En razón de ello, los siguientes subapartados se estructuran en torno al continuo cambio-continuidad respecto al statu quo. El primero está dedicado al análisis de los posicionamientos de los organismos internacionales. El segundo, hace lo propio con los organismos regionales. Finalmente, se analiza sucintamente el posicionamiento a nivel de países, principalmente de Estados Unidos y las potencias de Eurasia: China y Rusia.

\section{Organismos internacionales}

\section{La postura de la JIFE en el régimen}

La JIFE se ha posicionado como el actor más antagónico a los cambios, lo que ha derivado en diversas acusaciones y enfrentamientos con aquellos países que dentro de sus fronteras nacionales buscan modificar el statu quo. Así, por ejemplo, los informes anuales de JIFE han denunciado sistemáticamente la política de los coffee shops de Holanda y, actualmente, las iniciativas desarrolladas a nivel estadual en Estados Unidos y la política de regulación en Uruguay. Asimismo, en diversas ocasiones, sus autoridades se han manifestado no solo sobre la convencionalidad de las políticas, sino también sobre los potenciales impactos de las iniciativas, lo que las ha llevado a entablar disputas mediáticas con autoridades de gobierno y a recibir críticas por "extralimitarse" de sus funciones.

Más allá de esto, es preciso señalar que desde el año 2015 se verifican algunas señales que, aunque tímidas, dejan entrever un desplazamiento hacia una postura de oposición a los cambios más moderada. En este sentido, se destaca la no reelección de Raymond Yans en la presidencia, quien fue sustituido por Lochan Naidoo y posteriormente por Werner Sipp. Estas nuevas autoridades, aunque continúan con 
su labor de control de convencionalidad, han mostrado una actitud más abierta al diálogo con los países que ensayan nuevas alternativas. No obstante, se puede afirmar, al menos de forma parcial, que el organismo se posiciona como un verdadero "guardián" de las convenciones, en su interpretación más estricta, reaccionando como consecuencia ante los intentos de política que propugnan por una mayor flexibilidad en su aplicación.

\section{La postura de UNODC}

La postura de UNODC en el régimen ha sido, tradicionalmente, de alineamiento con el paradigma hegemónico de drogas. No obstante, su dependencia de la Comisión de Estupefacientes y, por lo tanto, de las posiciones de los distintos Estados nacionales, la convierten en una agencia más permeable a las dinámicas políticas que la JIFE, que descansa en el juicio de una burocracia "experta” más independiente. Así, si bien sus posicionamientos son usualmente consistentes con la opción prohibicionista, mayoritaria en el concierto de las relaciones internacionales, en ocasiones las visiones alternativas encuentran algunos canales de expresión. Y a la luz de la comparación con la JIFE, aparece como un actor más abierto a las demandas de flexibilidad, lo que, claro está, puede responder también a su diferente naturaleza institucional.

\section{La postura de la OMS}

La OMS participa formalmente en el régimen de drogas al proponer las clasificaciones de las sustancias en las listas de las convenciones que luego la Comisión de Estupefacientes ratifica o modifica. La postura de la OMS respecto a la problemática de las drogas ha ido sufriendo modificaciones. Entre fines de los ochenta y principios de los noventa países europeos como Suiza, Reino Unido y Holanda comenzaron a desarrollar políticas de reducción de daños, siendo muy criticados por ello. En cambio, la OMS emitió un comunicado afirmando que correspondía a los Estados miembro de la ONU definir las políticas de drogas que fueran necesarias en sus jurisdicciones por razones de 
salud pública, lo que significó un espaldarazo a estas políticas². En la actualidad, la organización apoya el paradigma de reducción de daños ${ }^{3}$.

En cualquier caso puede percibirse una tensión entre los expertos técnicos de tendencia más conservadora y tradicional y los representantes políticos, que tienden a ser más abiertos.

\section{El rol del sistema ONU de protección de DDHH}

La introducción del sistema ONU de protección de los derechos humanos representa, comparativamente, un desafío aún mayor. Desde el punto de vista legal, las normas de derechos humanos son jerárquicamente superiores a las convenciones de drogas, lo que otorga un argumento poderoso para limitar la implementación de medidas derivadas del régimen de drogas que puedan atentar contra estos derechos. Por ello, aunque no se cuenta con una agencia burocrática al estilo de la OMS, los países más abiertos a políticas de drogas flexibles se esfuerzan por incorporar el tratamiento de este tema en el Consejo de Derechos Humanos de la ONU y en la agenda del Alto Comisionado para los Derechos Humanos de ONU, así como en ONUSIDA.

El involucramiento del sistema ONU supone un viraje desde el enfoque basado en el control y la represión hacia otro que pone el eje en la protección y promoción de los derechos humanos. Ello redunda en la desjerarquización del paradigma hegemónico de drogas.

\section{Organismos regionales}

\section{La postura de OEA y CICAD}

En los últimos años, la postura de la OEA ha sido, esencialmente, removedora. Cabe señalar el contexto en el que se dio este proceso, el cual coincidió con un cambio de enfoque del problema de las drogas

\footnotetext{
2 Agradecemos a Raquel Peyraube por ponernos en conocimiento de este hecho.

3 Ver: http://www.who.int/hiv/topics/idu/es/
} 
en Colombia, México, Guatemala y el nuevo régimen propuesto para el cannabis en Uruguay. También hay que tener en cuenta el proceso llevado adelante en Estados Unidos. Es así que en mayo del año 2013 el secretario general del organismo, José Miguel Insulza, presentó un informe que había sido encargado por los jefes de Estado de los países miembro en la Cumbre de las Américas de 2012 al presidente de Colombia. El mismo se tituló Escenarios para el problema de las drogas en las Américas (2013-2025) y recogió por primera vez la posibilidad de que existan distintas alternativas para el abordaje del problema drogas como, por ejemplo, la despenalización y la legalización de la marihuana como una opción.

\section{La postura de UNASUR}

Producto de las características institucionales de esta organización, su postura descansa fuertemente en las posiciones y acuerdos a los que arriban los países miembro. Dentro de la región conviven distintas posturas que van desde las más conservadoras hasta aquellas que propugnan por la flexibilidad y la diversidad de abordajes y, puesto que se requiere del consenso para la toma de decisiones, con frecuencia las delegaciones ejercen su poder de veto. Así y todo, UNASUR finalmente logró acordar una posición común de cara a UNGASS, plasmada en el documento Visión regional del Consejo Suramericano sobre el problema mundial de las drogas de la UNASUR para UNGASS 2016, acordado en Montevideo en agosto de 2015. Allí se mencionan distintos elementos generales que derivan de la dificultad de lograr acuerdos, aunque dejando espacio para la ejecución doméstica de alternativas. En definitiva, UNASUR también se posiciona como un actor favorable a la flexibilidad, aunque no sin antes atravesar duras negociaciones internas y en un permanente escenario de flujo y reflujo.

\section{La postura de CELAC}

Apenas al año de empezar a discutir el tema drogas, la CELAC consiguió alcanzar una posición común de cara a UNGASS, conceptualmente similar a la de UNASUR. Lo hizo, además, antes que la organización sudamericana. Los participantes en las negociaciones 
cuentan que en el acuerdo también hubo algunas dificultades puesto que delegaciones como las de Perú y Cuba se mostraban reticentes a aceptar una posición que contemplara la existencia de nuevos enfoques frente al tema. No obstante, finalmente la Declaración de Quito del 22 de mayo de 2015, que presenta la postura del organismo, defiende la incorporación de los derechos humanos como un componente de las políticas de drogas y reconoce la potestad de los países de formular las políticas teniendo en cuenta sus realidades.

\section{La postura del MERCOSUR}

De cara a UNGASS 2016 el MERCOSUR acordó la Declaración de Brasilia-Puntos de convergencia de los Estados parte y asociados del MERCOSUR frente a la UNGASS 2016. De este documento cabe destacar que se entiende que el problema mundial de las drogas debe abordarse a través de un enfoque integral, multidisciplinario y equilibrado y basado en el principio de responsabilidades comunes y compartidas, con pleno respeto de los derechos humanos. Es interesante, asimismo, señalar que este afirma "[...] que el marco jurídico de las tres convenciones de la ONU en materia de drogas es suficientemente amplio y flexible, lo que nos permite abordar las diferentes experiencias nacionales...". En otras palabras, MERCOSUR presenta una postura de mínimos comunes en la que, si bien no se propone una transformación radical del statu quo, se promueve una interpretación flexible del marco jurídico internacional para permitir el desarrollo de alternativas.

\section{La relación entre el régimen internacional y los países y las regiones}

\section{La postura de Estados Unidos}

Históricamente, Estados Unidos ha participado en el régimen internacional de drogas con un peso determinante en la creación del marco jurídico internacional para las sustancias psicoactivas y sus posteriores reformulaciones. Desde los tiempos de la llamada "ley seca", pasando por el auge de la War on Drugs a finales de la década 
de los sesenta y comienzos de los setenta, el país ha sostenido una estrategia de guerra frontal a las drogas (Magnus, 2015).

Actualmente conviven en el país estados que han legalizado el uso de la marihuana con fines medicinales, otros donde la posesión es ilegal pero no está criminalizada, otros donde es completamente ilegal y finalmente aquellos en los que es legal para todos los usos. El discurso internacional ha tenido un importante viraje y en el ámbito doméstico las presiones por un "enfoque más humano" son aún mayores ${ }^{4}$. Tal y como destacó la misión diplomática de Uruguay en dicho país, luego de la aprobación de enmiendas para regular el cannabis recreativo en Colorado y Washington en noviembre de 2012, en conjunto con las aprobadas en el año 2015 por Alaska y Oregón y posteriormente por el propio Distrito Federal (Washington D.C.),

[...] la discusión doméstica se centró en la demanda de un cambio en el enfoque respecto a las políticas de combate a la droga por parte de los EEUU, la revisión de su estrategia, los efectos en el consumo y en las políticas contra el crimen organizado y el narcotráfico, mientras que por otra parte surgió un debate en la agenda pública referido a la compatibilidad de la legislación federal con las iniciativas de legalización de la marihuana para consumo recreativo en los estados... (Misión Diplomática Uruguay en Estados Unidos, entrevista semiestructurada, 15 de febrero de 2016).

De igual forma, dicha postura puede advertirse en un doble sentido. Por un lado, mediante el inesperado aval de la diplomacia estadounidense a la política llevada adelante por Uruguay (Semanario Búsqueda, 4/2/2016) y, por otro lado, producto de la posición asumida por Estados Unidos en UNGASS 2016 donde promueve un revisionismo acotado dejando de lado su histórica postura obstruccionista (Comini y Tokatlián, 2016; Jelsma, 2016). En definitiva, Estados Unidos se encuentra en un proceso de cambios internos con consecuencias sistémicas a nivel internacional.

\footnotetext{
4 Incluso, Boidi, Cruz y Queirolo (2015) encuentran que la opinión pública estadounidense apoya la regulación del cannabis en mayor medida que la uruguaya.
} 


\section{La postura de las potencias de Eurasia (China y Rusia)}

Desde el comienzo del debate internacional sobre el cannabis, Rusia se ha mostrado contraria a incluir en su agenda procesos de regulación. Esta actitud se vio reflejada durante los sucesos de regulación en Uruguay. En este sentido, se destacan los encuentros que, luego de la regulación en Uruguay, el entonces vicepresidente de la República, Danilo Astori, mantuvo con la presidente del Consejo de la Federación, Valentina Matvienko, y el ministro de Relaciones Exteriores de la Federación de Rusia, Sergeui Lavrov. Según relata la misión diplomática uruguaya, durante los encuentros, encuentran:

[... Tanto la Sra. Matvienko como el Sr. Lavrov recalcaron su preocupación por la implementación de la ley, considerándola como un verdadero peligro para la seguridad pública. Del mismo modo, mostraron inquietud por la compatibilidad de la nueva ley uruguaya con los avances logrados en las convenciones de Viena... (Misión Diplomática Uruguay en Rusia, entrevista semiestructurada, 9 de diciembre de 2015).

La situación en China no difiere mayormente de la de Rusia e inclusive es aún más drástica. Los escasos artículos en medios de prensa de ese país reflejan una postura contraria a la adoptada por Uruguay, los Países Bajos y Estados Unidos. En tal sentido, se destaca la publicación de notas que refieren a los problemas de implementación de la ley uruguaya. Según afirma la misión diplomática uruguaya en China, esto se debe principalmente a que:

[...] la legislación china condena fuertemente la posesión, venta, tráfico y cultivo de cannabis, constituyendo el tráfico un causal de pena de muerte [...] El presidente Xi Jinping ha endurecido esta política. Prueba de ello, fue la detención de reconocidas celebridades chinas a fines del 2014. En algunos casos se penalizó el consumo y en otros la pena recayó sobre dueños de propiedades donde se constató el consumo de cannabis [...] en general, tanto la prensa, la opinión pública y la academia coinciden con la postura adoptada por el gobierno y no se perciben cambios a 
corto plazo en cuanto a liberalización de este producto... (Misión Diplomática Uruguay en China, entrevista semiestructurada, 9 de diciembre de 2015).

Lo anterior se refleja en las posiciones asumidas por estos países en UNGASS 2016. En dicha oportunidad, ambos mantuvieron un alto perfil al promover un profundo obstruccionismo (Comini y Tokatlián, 2016). Ya en los documentos preparatorios para dicha sesión, China adelantaba su decisión de oponerse firmemente a la legalización de las drogas en cualquier forma, mientras que Rusia aludía a la necesidad de que los Estados cumplan plenamente sus obligaciones en virtud de las convenciones internacionales de fiscalización de drogas, incluida la limitación del uso de drogas solo con fines médicos y científicos.

\section{Conclusiones sobre el régimen y los actores}

En definitiva, a nivel internacional, los actores cubren todo el espectro de posturas a lo largo del continuo. A nivel regional, este no es el caso. Al contrario, los actores se ubican más cercanos al polo de flexibilidad que a su opuesto, o a lo sumo en una posición equidistante, mostrando un clima de mayor apertura hacia nuevas iniciativas. Es particularmente relevante notar que, si bien el histórico hegemón del régimen, Estados Unidos, se ha mostrado proclive al cambio, tanto China como Rusia mantienen y refuerzan las posturas pro statu quo. En otras palabras, y contrariamente a lo encontrado en otras áreas de política, la tendencia actual hacia un sistema unipolar en esta área parece reducir más que ensanchar las alternativas de política, puesto que el tradicional hegemón muestra cierto grado de flexibilidad mientras que los polos de poder emergentes se posicionan como los más férreos defensores del statu quo. De todos modos, ni la capacidad ni, sobre todo, la voluntad de trasladar preferencias en líneas de política - con la inversión/costos que ello conlleva - es evidente por parte de los emergentes. Por ende, la flexibilidad estadounidense, sumada a las posiciones latinoamericanas, genera un marco internacional actual más permeable a ciertas innovaciones si se lo compara con la realidad de décadas anteriores. 


\section{La estrategia uruguaya y sus resultados}

\section{Contexto general de la política exterior}

La política exterior del gobierno uruguayo encabezado por José Mujica, y de los gobiernos del Frente Amplio en general, se ha caracterizado por la tensión entre privilegiar una relación más cercana con los vecinos latinoamericanos o una relación bilateral más estrecha con Estados Unidos (Hernández Nilson et al., 2016). El primer gobierno de la izquierda buscó mantener un equilibrio mediante una apuesta al llamado regionalismo abierto, mientras que el segundo, presidido por Mujica, apostó por una relación más cercana con Brasil, siguiendo su estrategia de regionalismo sudamericano (López, 2013). Fuera del terreno económico-comercial, el gobierno implementó la estrategia diplomática tradicional del país de presentarse como defensor del derecho internacional, a lo que incorporó una activa promoción de los derechos humanos que lo llevó a ocupar un lugar en el Consejo de Derechos Humanos de Naciones Unidas entre 2010 y 2012.

Desde su asiento en el Consejo, Uruguay promovió la problematización de la estrategia de guerra contra las drogas desde una perspectiva de derechos humanos. Sin embargo, no lo hizo a partir del manejo de la regulación del cannabis como una de las soluciones. Pues, de hecho, dicha política no era parte de la agenda del gobierno en ese entonces, ni había sido una bandera de campaña de cara a las elecciones nacionales de 2009. Por lo tanto, era imposible que la iniciativa formara parte de los lineamientos proyectados para la política exterior del país. En cambio, como se verá, la construcción de una estrategia internacional tuvo una naturaleza netamente reactiva, decidida como respuesta a los cuestionamientos provenientes desde el exterior. De todos modos, la vinculación con los derechos humanos y la previa participación en el Consejo son aspectos que el gobierno capitalizará posteriormente en su estrategia de defensa. 


\section{Etapas de la política internacional del cannabis}

La política internacional de presentación de la regulación del cannabis en el mundo tuvo su origen tras las críticas recibidas desde el ámbito internacional, con las acusaciones de la JIFE a la cabeza. A partir de ese momento, el gobierno implementó una estrategia internacional dirigida a justificar la iniciativa, generar aliados y planear cómo contener las potenciales críticas.

Es posible distinguir tres etapas para analizar la estrategia de defensa a nivel internacional. La primera de ellas se inició con el tratamiento del proyecto en la Cámara de Diputados y se extendió hasta la promulgación de la ley a inicios de 2014. La segunda etapa comenzó tras la aprobación de la ley y duró hasta el cambio de Administración a inicios de 2015. Finalmente, la tercera fase comprende la gestión del segundo mandato de Tabaré Vázquez a partir de marzo del 2015.

\section{Etapa I. Una política reactiva frente a los desafíos internacionales}

El inicio del tratamiento del proyecto de regulación del cannabis en Uruguay en 2012 supuso una inmediata y virulenta reacción de la JIFE. Además de señalar que la medida "contravendría lo dispuesto en la Convención Única de 1961” (El País, 20/11/2013), resaltando así la supuesta ilegalidad de la iniciativa, su presidente Raymond Yans manifestó ante medios internacionales que "este es un tipo de visión propia de piratas, que un país decida no retirarse de la Convención y tampoco respetarla" (Misión Diplomática Uruguay en Austria, entrevista semiestructurada, 15 de febrero de 2016). Además, más allá de la evaluación de la legalidad, una vez aprobada la ley avanzó en una evaluación de sus potenciales consecuencias sociales, señalando:

[...] la decisión del legislador uruguayo no tiene en cuenta su impacto negativo en la salud, ya que los estudios científicos confirman que el cannabis es una sustancia adictiva con graves consecuencias para la salud de las personas [...] En particular, el uso y abuso de cannabis por parte de los jóvenes puede afectar gravemente a su desarrollo... (La Nación, 12/12/2013). 
Sin el mismo tono, pero también con una perspectiva crítica, se expresó el director de UNODC. Y en la Comisión de Estupefacientes, países como Pakistán e Irán promovieron la inclusión de la siguiente frase en la Declaración Ministerial Conjunta de alto nivel de 2014, que se negociaba durante el 2013: “expresando preocupación por los movimientos hacia la legalización de ciertas drogas ilícitas en algunas partes del mundo". Argelia acompañó este planteamiento, a la vez que propuso añadir: "in particular initiatives and legislative proposals that intend to regulate cannabis for other than medical and scientific purposes". Si bien el párrafo fue finalmente retirado — a instancias de Uruguay-, en su momento la propuesta fue secundada por Egipto, China, Marruecos, India, Rusia, Suecia, Indonesia y Sudáfrica (Misión Diplomática Uruguay en Austria, entrevista semiestructurada, 15 de febrero de 2016), lo que muestra que esta visión encontraba cabida en distintas regiones del mundo.

Rusia fue particularmente activa en su rechazo, con varios comunicados que lamentaban la iniciativa uruguaya y compartían la opinión de la JIFE (Misión Diplomática Uruguay en Rusia, entrevista semiestructurada, 9 de diciembre de 2015). Estados Unidos, en cambio, reconocía la potestad del pueblo uruguayo de decidir sus políticas, pero recordaba la necesidad de cumplir con los compromisos internacionales (La Diaria, 13/12/2013). Mientras que en la región, países como México criticaban el uso de "estrategias unilaterales", Brasil, en cambio, no se expresó públicamente sobre la medida, lo que se entiende en el marco de las excelentes relaciones bilaterales que mantenían los gobiernos de Mujica y Rousseff. No obstante, en privado, altos representantes del gobierno brasileño manifestaron a sus pares uruguayos sus preocupaciones respecto a los potenciales efectos de la política en Brasil, así como sobre una posible explosión del turismo cannábico. En definitiva, Uruguay enfrentaba un ambiente internacional y regional hostil a su política.

Ante esto, el gobierno uruguayo no contaba con una estrategia de respuesta definida (Calzada, J., comunicación personal, 3 de octubre de 2015). Los impulsores de la política no previeron una reacción internacional tan hostil, incluso si la legislación propuesta podía, 
potencialmente, chocar con las convenciones de otras. $\mathrm{Y}$ al momento de generar una respuesta, de hecho, al interior del gobierno las posiciones eran divergentes. Frente a los cuestionamientos, aparecieron dos opciones de política en disputa: una más activa, que proponía desafiar el orden internacional establecido y, si las circunstancias lo exigían, denunciar las convenciones; otra más reactiva, que buscaba limitarse a la defensa del espacio para desarrollar la iniciativa sin cuestionar el orden vigente. La primera era defendida por el presidente de la JND, y contaba con el apoyo —e incluso impulso- de la sociedad civil, en tanto que la segunda representaba principalmente la opinión de la Cancillería.

Sin embargo, a pesar de la falta de previsión, los actores mostraron una rápida capacidad de reacción y, sobre todo, de coordinación interna. Se definieron los voceros de las distintas agencias —el presidente de la JND, el secretario de la JND y el vicecanciller-, a los que se sumó el embajador de Uruguay ante la OEA — quien había sido el secretario de la JND y contaba con un amplio reconocimiento internacional en el tema- y en ocasiones el propio presidente Mujica. Asimismo, se instaló una figura de enlace permanente entre la Cancillería y la JND.

Como resultado, el gobierno uruguayo fue capaz de construir un discurso homogéneo, sin fisuras, que en buena medida ensambló los componentes con mayor potencial de las dos posturas iniciales. La respuesta internacional, por un lado, se basó en presentar las particularidades del país, como la imposibilidad de penalizar el consumo y la consecuente necesidad de proveer alguna vía de acceso legal para proteger los derechos humanos y la salud de los consumidores. Remarcando, a su vez, la no voluntad de exportar el modelo. Y, por el otro, al introducir estas problemáticas al debate, comenzó a cuestionar, ya en términos generales, la posibilidad de aplicar estrictamente las convenciones de drogas sin incumplir las obligaciones emanadas de los tratados internacionales de derechos humanos. Asimismo, la noción de regulación por oposición a liberalización irrestricta, y la idea de experimento, sujeto a evaluaciones y potenciales rectificaciones, y además abierto a las sugerencias de la comunidad internacional, comenzaron a estar cada vez más presentes en el discurso uruguayo. 
Con estas armas, Uruguay comenzó a ensayar su defensa internacional. La primera trinchera elegida para esto fue el epicentro del régimen regional: la OEA. Dicha elección es el resultado de la combinación de tres factores: un secretario general del organismo afín a la iniciativa uruguaya, un gobierno de Estados Unidos dispuesto a no ejercer su poder de veto sobre la discusión de nuevos enfoques, y la presencia de Milton Romani como embajador uruguayo ante la OEA. Particularmente, el Informe Insulza fue leído por Uruguay como una legitimación de su política, más allá de que este no respalda en particular ninguno de los cuatro escenarios que presenta.

Tras esto vino la respuesta a la JIFE, que tuvo su máxima expresión en la participación del vicecanciller en la $109^{a}$ sesión del organismo en Viena. Allí, manifestó que Uruguay era un país cumplidor del derecho internacional, tanto de las convenciones de drogas - las que de acuerdo al gobierno no se estaban incumpliendo- como de los instrumentos de derechos humanos. Y que al no estar penalizado el consumo en Uruguay, por ser un acto privado, se debía proteger a los consumidores de la necesidad de acudir al narcotráfico. Además, agregó que el país se destacaba por su lucha contra el narcotráfico y el lavado de activos, lo que le otorgaba autoridad moral para emprender una regulación responsable del mercado de marihuana y repudió las calificaciones que Raymond Yans había vertido sobre el país 5 .

Al mismo tiempo, el presidente Mujica, acostumbrado a la diplomacia presidencial y portador de una elevada popularidad internacional, intervenía ante la prensa y se reunía con jefes de Estado y de gobierno para aclarar sus inquietudes, con la visita a la presidenta Rousseff como punto sobresaliente. Y, entre tanto, el presidente de la JND participaba en la Comisión de Estupefacientes y mantenía allí una intensa agenda de reuniones bilaterales con representantes de otros Estados, intentado trasladar así el locus del debate desde la JIFE a este espacio intergubernamental.

5 Discurso de Luis Porto ante la JIFE. 
Por otra parte, y en colaboración con las bases de apoyo sociales a nivel nacional, el gobierno logró consolidar importantes apoyos y alianzas con expertos internacionales y organizaciones de la sociedad civil internacional. Así, mediante la organización de un debate abierto en Washington, promovido por la delegación uruguaya en la OEA, representantes del Washington Office for Latin America (WOLA), del Inter-American Dialogue y del Centro Carter, expresaron su apoyo a la iniciativa uruguaya (La Diaria, 17/9/2013). Incluso, WOLA otorgó una distinción a Milton Romani por la promoción del enfoque de derechos humanos en las políticas de drogas. Y mediante una carta dirigida al presidente José Mujica, la organización saludó al país por su "actitud pionera" en el tema (Portal Presidencia Uruguay, 24/10/2013).

Con esta diplomacia activa, además de capitalizar el apoyo de la sociedad civil nacional e internacional y de expertos internacionales, Uruguay logró apaciguar las preocupaciones de un jugador regional clave como Brasil. Y, al mismo tiempo, se aseguró el no veto de Estados Unidos al punto que su embajadora reconoció que la iniciativa era un "asunto interno" del país. El discurso coherente de todos los actores de gobierno, su disposición al diálogo, y el refuerzo de la lucha contra el narcotráfico y el lavado de activos permitieron incluso contener, al menos en parte, los cuestionamientos de los Estados más conservadores a nivel internacional. Sin embargo, la búsqueda de apoyos estatales explícitos fue tan ardua como infructuosa: salvo Guatemala, Colombia, y unos pocos gobiernos europeos como Italia, Uruguay no logró construir alianzas interestatales a su favor.

La relación con los principales actores del régimen internacional resultó aún más desalentadora. Tanto desde UNODC, como principalmente desde JIFE, se mantuvo el tenor de las críticas. Si bien este último organismo pidió disculpas por las declaraciones ofensivas de su presidente, los cuestionamientos sustantivos se mantuvieron incambiados. En definitiva, al finalizar este período, el gobierno uruguayo había logrado gestionar exitosamente el desafío internacional, presentando un discurso coherente y coordinado, y asegurando el espacio de autonomía necesario para concretar su iniciativa, sin cas- 
tigos ni sanciones formales de ningún tipo. A nivel regional, incluso, logró evitar costos relevantes en términos de imagen, pero este no fue el caso a nivel internacional. En conclusión, el país estaba todavía claramente en una posición defensiva.

\section{Etapa II. Tras la promulgación, la iniciativa}

Sorpresivamente, tras la promulgación de la ley el clima internacional respecto a la iniciativa tuvo un vuelco favorable a Uruguay. Una interpretación propuesta por un integrante de la sociedad civil en un grupo de discusión es que "internacionalmente, todos estaban esperando que dijeras se legalizó. Y así iba a estar lleno de turistas fumando, se iban a vender porros por todos lados y eso no sé si no habla bien, porque no pasó". Lo cierto es que al mes de la promulgación el gobierno uruguayo consiguió dos victorias clave, una en el plano regional y otra en el internacional. La primera fue asegurarse el apoyo del secretario general de la UNASUR, el expresidente de Colombia Ernesto Samper. Mientras que la segunda tuvo como epicentro la $57^{\circ}$ reunión de la Comisión de Estupefacientes.

Allí, inicialmente, Argentina y Brasil manifestaron su tranquilidad con la medida, y tras esto Colombia, Ecuador, México y Guatemala expresaron su apertura e interés hacia la misma. Paralelamente, la delegación uruguaya organizó un side event junto con WOLA, el Transnational Institute y el International Drug Policy Consortium, donde profundizó en el contenido de la reforma. Finalmente, con todos estos apoyos, el gobierno logró pasar a la ofensiva al conseguir aprobar una moción en la Comisión de Estupefacientes, copatrocinada por Guatemala, Ecuador, Colombia y México, que instaba a integrar al alto comisionado para los Derechos Humanos de ONU, la OMS, la FAO y el PNUD a las discusiones sobre drogas que tendrían lugar en la Asamblea General de la ONU en 2016 (La República, 23/3/2014).

Sobre este nuevo contexto, el secretario de la JND señalaba: "Hace tres años, cuando se inició este debate (...) un modelo alternativo a la política de droga era visto como algo fuera de sus cabales. Hoy 
nos respetan y nos miran con atención y sin sorna" (La República, 23/3/2014). Mientras que intentando ensanchar la base de apoyo, buscaba introducir el tema en CELAC, exponiendo sobre el "abordaje integral en el combate contra las drogas con énfasis en la salud pública y los derechos humanos" (Portal Presidencia Uruguay, 20/5/2014) en una reunión del organismo.

Paralelamente, tras la reglamentación de la ley en mayo de 2014, la defensa internacional incorporó un nuevo elemento que consistió en diferenciar el modelo regulatorio uruguayo de las iniciativas estaduales en Estados Unidos. Así, representantes uruguayos expresaban en CICAD que "[en nuestro caso] no se trata de una liberalización del mercado, ya que hay una fijación del precio por parte del Estado, no existiendo ni marcas ni publicidad" (Portal Presidencia Uruguay, 26/4/2014).

Es que como explicó uno de los redactores de la ley durante un grupo de discusión realizado para esta investigación: "cuando Uruguay aprueba esta ley, en el concierto internacional ya había voces relevantes que planteaban este tema. En lo que innovamos verdaderamente es en que elaboramos un modelo". Y, de acuerdo con otro participante, este es altamente valorado por los expertos internacionales en tanto incorpora los pilares de derechos humanos, salud pública y seguridad interna, y consiste en una full regulation que contempla los distintos usos del cannabis. Por ende, su promoción a nivel interestatal contribuía a legitimar la iniciativa. En esta línea, José Mujica concedió una extensa entrevista a la BBC donde profundizó en las diferencias con las iniciativas estadounidenses: "Lo que pasa es que no lo hacen con el espíritu de experimentar ni nada. Van derecho por la vía del mercado, a vender a cara de perro y se acabó” (BBC, 7/5/2014).

Por otra parte, fue tras la reglamentación que llegaron, después de mucho tiempo, las primeras noticias positivas desde los principales órganos del régimen internacional. En la JIFE, Raymond Yans no fue reelegido como presidente, decisión que altos cargos uruguayos vincularon con las hostiles declaraciones que emitiera sobre Uruguay en diciembre de 2013. En tanto que UNODC dio un paso más, y 
por medio de su director regional reconoció por primera vez que se podría "aprender mucho" de la experiencia uruguaya, remarcando la importancia del Comité Científico Asesor integrado por representantes internacionales, e instando a "[dejar] que hagan su tránsito de la ley y veamos qué cosas buenas se pueden incluir en las políticas públicas y las malas rechazarlas" (El Espectador, 9/5/2014).

En esta etapa, y a diferencia de la anterior, los principales desafíos internacionales tuvieron un origen doméstico. Por ejemplo, la prensa internacional se hizo eco de las críticas de los empresarios uruguayos a la reglamentación de la ley, basadas en la supuesta ausencia de controles en el mundo del trabajo. Y la Federación Internacional Farmacéutica, a instancias de la Asociación de Química y Farmacia del Uruguay, expresó su oposición a la venta de marihuana en las farmacias (El País, 22/6/2014). A su vez, en medios de varios países comenzaron a aparecer críticas por las demoras y las dificultades para implementar la dimensión más novedosa de la ley, es decir la venta al público en farmacias.

Las elecciones generales de 2014 también tuvieron su impacto. Los principales líderes políticos de la oposición se opusieron a la iniciativa a nivel doméstico, en algunos casos en forma parcial — venta en farmacias - y en otros completamente. Por ende, no acompañaron la estrategia internacional del gobierno. Desde el exterior esto tuvo repercusiones, al punto que varios medios internacionales especularon con que la iniciativa tal vez nunca llegaría a implementarse (El Nuevo Herald, 1/8/2014; Infobae, 1/8/2014, entre otros). Incluso algunos líderes opositores, en contacto directo con la prensa internacional, manifestaron preocupaciones como las relacionadas con el turismo cannábico (Montevideo Portal, 9/12/2013), o con la señal que se trasmitía al exonerar las ventas de marihuana de un impuesto nacional ( $A B C$ de Paraguay, 9/5/2014).

No obstante, en el plano internacional, el gobierno continuaba cosechando apoyos, como el del Observatorio Europeo de las Drogas y Toxicomanías (BBC, 27/5/2014), de varios fiscales antidrogas de la región (ElPaís, 2/7/2014), e incluso del mercado financiero internacional 
que, mediante el influyente The Wall Street Journal, señalaba las crecientes oportunidades de negocios para la industria cannábica, no solo recreativa sino también medicinal (The Wall Street Journal, 23/5/2014).

El cambio de clima permitió que varios países de la región, inspirados en la política uruguaya, se plantearan modificar o al menos discutir sus propias políticas. En Colombia, representantes uruguayos compartían su experiencia mientras el gobierno colombiano discutía un proyecto para legalizar el uso medicinal del cannabis (Montevideo Portal, 15/8/2014). En Argentina, el ministro de Seguridad planteaba emular la estrategia de Uruguay, aunque no todo el gobierno acompañaba su visión (Montevideo Portal, 21/7/2014). En Chile, de acuerdo al diario ElPaís, "las autoridades han evaluado el proceso seguido en Uruguay respecto a la regulación de la marihuana, ya que se estudian iniciativas de las mismas características" (El País, 2/7/2014). Y en Paraguay, el diario Última Hora informaba: "Analizan utilizar modelo uruguayo de regulación de la marihuana" (Última Hora, 22/10/2014). El presidente mexicano Peña Nieto sintetizaba perfectamente la nueva percepción regional sobre el costo percibido de innovar: "Vemos que Uruguay ya lo aprobó. Y que eso tampoco tuvo ningún efecto en el orden de la relación diplomática" (ElComercio, 26/8/2014).

Como corolario de esto, Uruguay consiguió, con el copatrocinio de Argentina y el apoyo de Ecuador, México, Colombia y Guatemala, aprobar una resolución vinculando la problemática de drogas con los derechos humanos, por unanimidad, en la OEA. Reafirmando, así, un pilar del discurso internacional del país en este escenario.

En definitiva, si la imagen internacional de Uruguay había sufrido al inicio un impacto negativo por las acusaciones de que la nueva política violaba las convenciones de drogas, ahora esta se revalorizaba, producto, paradójicamente, de la misma ley. El país presentaba un abordaje novedoso de regulación bien evaluado por los expertos internacionales que lo diferenciaba de la imagen de Colorado y sus excesos. A nivel regional era mayoritariamente apoyado e internacionalmente la iniciativa no había sido vetada por Estados Unidos, UNODC reconocía que la experiencia 
uruguaya podía servir como aprendizaje y la JIFE, sin ceder en sus críticas, reducía la virulencia de sus acusaciones.

Este clima internacional favorable a Uruguay se reflejaba en la prensa internacional, en las consideraciones de distintas personalidades de relieve mundial y en la apertura de nuevos países al enfoque. Como señaló con contundencia un participante de un grupo de discusión: "yo siempre dije que esto no iba a ser una decisión factible porque nadie iba a pagar el costo político de esto. Y el Pepe (Mujica) no solo no lo pagó, sino que lo capitalizó, y eso fue brutal”.

\section{Etapa III. Continuidad y apuesta de cara a UNGASS 2016}

Si bien las elecciones determinaron la continuidad del Frente Amplio en el gobierno, el inicio del mandato de Tabaré Vázquez estuvo marcado por la incertidumbre respecto al tema drogas, producto de la escéptica postura inicial frente al proyecto del mandatario. No obstante, la designación de Milton Romani como secretario de la JND y la continuidad de buena parte del equipo anterior significaron una reafirmación de la línea trazada, tanto a nivel nacional como internacional. La diferencia, en todo caso, sería el fin de la diplomacia presidencial propia de Mujica y una mayor centralidad de la secretaría de la JND en el accionar externo.

Las dos primeras respuestas que tuvo que ensayar el nuevo gobierno tuvieron como epicentro al régimen internacional. Una fue la publicación del informe de 2014 de la JIFE en donde se volvía a cuestionar la iniciativa uruguaya al señalar que violaba las convenciones y ponía en riesgo el sistema internacional de fiscalización. Tras esto, representantes uruguayos se reunieron en Viena con los renovados integrantes del organismo para explicar nuevamente el alcance de la iniciativa y enfatizar en que no se trataba de una liberalización de mercado. Participantes del encuentro señalan que desde aquí cambió la postura del organismo, el cual se mostró dispuesto a escuchar y a visitar Uruguay (Misión Diplomática Uruguay en Austria, entrevista semiestructurada, 15 de febrero de 2016). En tanto que la otra fue la participación en la 58 a Comisión de Estupefacientes. Allí la delegación aprovechó la 
ocasión para mantener encuentros bilaterales con las delegaciones de Cuba y Perú que, a nivel regional, mostraban las mayores resistencias a aceptar los nuevos enfoques. Y durante la intervención en la Comisión, Uruguay desplegó todos los argumentos que venía sosteniendo: la incorporación de la perspectiva de derechos humanos, la incorporación de otros actores como OMS y PNUD al debate, la necesidad de probar con nuevos modelos y la no orientación del gobierno uruguayo a la exportación de su experiencia. Adicionalmente, se trazó una similitud entre las políticas de cannabis y de tabaco vigentes en el país.

Como balance de la participación, Romani expresaba que "varios países plantean cambiar el enfoque prohibicionista para competir al narcotráfico", al punto que el representante de Estados Unidos le mencionó: "estamos juntos en esta experiencia. Los tiempos están cambiando" (Portal 180,12/3/2015). También mencionó el apoyo a este enfoque de países como Colombia, México y Guatemala y afirmó que Argentina y Brasil le manifestaron que si bien no seguirían el mismo camino, "si les va bien los vamos a aplaudir" (La República, $11 / 3 / 2015)$.

A fines de marzo de 2015 Uruguay impulsó en el Consejo de Derechos Humanos de la ONU una resolución titulada "Contribución del Consejo de Derechos Humanos a la Sesión Especial de la Asamblea General de Naciones Unidas sobre el Problema Mundial de las Drogas". La misma fue copatrocinada por Colombia, Guatemala y Suiza, apoyada por Albania, Grecia, Brasil, México, Paraguay y Noruega, y aprobada por unanimidad (Portal Presidencia Uruguay, 12/4/2015), logrando así el objetivo de incorporar otros actores al debate. Por otra parte, durante una intervención en la ONU, Romani dio un paso más al condenar el uso del mecanismo de la pena de muerte frente a ofensas de drogas. Así, atendió a uno de los principales reclamos de la sociedad civil uruguaya que insistía en la necesidad de enmarcar a nivel internacional la política del cannabis dentro de las discusiones más generales sobre represión, drogas y derechos humanos.

También se proyectó una alianza con el alto comisionado para los Derechos Humanos (El País, 26/6/2015) y desde la presidenta pro 
témpore de UNASUR se consiguió alcanzar una posición común de cara a UNGASS al limar resistencias iniciales de países más favorables al status quo como Perú. Como resultado de todas estas iniciativas, el presidente de la Asamblea General de la ONU, Sam Kutesa, invitó a Uruguay, por su contribución a la lucha contra las drogas, a exponer en un debate preparatorio de UNGASS 2016 (Montevideo Portal, 24/4/2015), lo que significó otra victoria en términos de legitimidad para el país. Y de acuerdo con un participante de los grupos de discusión, los gobiernos de Irlanda y Canadá manejaban el modelo uruguayo como opción para regular el cannabis en sus países.

Como resulta evidente, el tejido de las más amplias alianzas posibles a nivel internacional era una pieza clave de la estrategia. Es que los objetivos del gobierno no eran solo reactivos, sino también propositivos: conseguir que UNGASS 2016 fuera el inicio de un régimen internacional de drogas en el que pudieran convivir distintas aproximaciones (La República, 11/3/2015).

No obstante, el gobierno aún tenía que superar el desafío más árido desde un punto de vista reactivo: su relación con la JIFE. En noviembre de 2015, se concretó la visita del organismo a Uruguay. En ella se evidenció que la relación entre el país y el organismo había pasado a un nuevo plano, dejando atrás la hostilidad anterior. Según manifestaron los integrantes de la delegación en reuniones mantenidas para esta investigación, su postura es que Uruguay continúa violando las convenciones sobre drogas, no obstante lo cual se destaca la seriedad y el trabajo de control que se viene desarrollando en torno a la ley.

De acuerdo con otro testimonio, el nuevo presidente Werner Sipp manifestó su satisfacción con la visita y la disposición a continuar evaluando con especial atención el proceso. Mientras que el miembro Alejandro Mohar dijo que el encuentro le "clarificó el proceso uruguayo" y que se iba del país con la visión de que "el esfuerzo de Uruguay no es liberar la marihuana ni legalizarla, sino que es un control de las drogas y demás sustancias tóxicas en un marco de salud pública y bienestar" (Misión Diplomática Uruguay en Austria, entrevista semiestructurada, 15 de febrero de 2016). 
Con este foco de conflicto reducido a su mínima expresión, el gobierno continuó su preparación de cara a UNGASS. En este sentido, Romani participó en una reunión en Cartagena convocada por Colombia, Suiza, México y Ghana, a la que concurrieron 39 Estados y en la que se acordó promover la creación de "un grupo de expertos que analice la consistencia de las convenciones que garantice la debida integración con los derechos humanos" (Montevideo Portal, 15/12/2015). Además, junto a Colombia, Guatemala y México se acordó promover la descriminalización de los usuarios, buscar alternativas a la prisión por ofensas menores de drogas y tender a reducir los niveles de violencia (La Diaria, 21/12/2015).

En resumen, se destaca que Uruguay mantuvo una política coherente, con una clara continuidad en los argumentos de defensa de la iniciativa. Y, además, que logró consolidar la tendencia iniciada en el período anterior, de pasar de una posición estrictamente defensiva a una que promueve, en alianza con otros actores, un régimen internacional de drogas en el que puedan convivir distintas visiones.

En el plano reactivo, el logro más importante fue reducir la intensidad de la crítica de la JIFE. Adicionalmente, el país evitó que surgieran nuevas dificultades con los países más reacios a los nuevos enfoques, como Rusia, China y el mundo árabe, y mantuvo la aprobación de Argentina y Brasil. Mientras que en el plano propositivo, consiguió avances tanto a nivel regional como mundial. En el primer caso, consolidó la alianza con países como Colombia, Ecuador, Guatemala y México, lo que le permite presionar por espacio para los nuevos enfoques sin ser la única cara visible de esta demanda de cambio. Además, al superar duras resistencias iniciales, logró consensuar posturas comunes a nivel de los distintos foros de cooperación política como UNASUR y CELAC de cara a UNGASS. En tanto que en el nivel internacional ensanchó el alcance de las alianzas de cara a la incorporación del enfoque de derechos humanos al conseguir el apoyo de varios estados europeos e incluso de algunos africanos.

Finalmente, en contraste con estos avances, es preciso señalar que quedó pendiente un desafío importante que tuvo un origen doméstico. 
En concreto, la falta de implementación de la modalidad de venta en farmacias privó al país de contar con una evaluación completa del funcionamiento de la ley para UNGASS, lo que hubiera dotado al gobierno de argumentos empíricos para presentar globalmente $s u$ experimento. Esta era una meta que el propio Romani se había planteado al asumir la nueva gestión (Portal 180,12/3/2015); sin embargo, el retraso en la puesta en marcha de este mecanismo no permitió cumplir cabalmente con dicho objetivo.

\section{Conclusiones del caso uruguayo}

Tras esta reconstrucción cabe preguntarse entonces, ¿cómo logró Uruguay el espacio de autonomía para desarrollar su política? Para dar respuesta a este interrogante, es ineludible mencionar en primer lugar el cambio de enfoque de Estados Unidos, principal creador y mecanismo de enforcement del régimen internacional de combate a las drogas. La postura permisiva de esta potencia que, producto de sus propios cambios internos, no bloqueó la reforma uruguaya, se revela como un factor clave. Otros países poderosos del régimen con posturas conservadoras, como China y Rusia, si bien se mostraron reticentes al cambio, tampoco asumieron un liderazgo proactivo en el objetivo de bloquear la iniciativa. Mientras que a nivel regional, es evidente que el no veto de Estados Unidos es igualmente significativo.

No obstante, la explicación es incompleta si no se incorporan los factores internos. La presentación de la política como una regulación antes que una liberalización, con el control del Estado como centro, y el carácter experimental de la reforma fueron argumentos decisivos para persuadir a la comunidad internacional y regional. La construcción de un enfoque contemplativo de la salud, la seguridad y los derechos humanos, otorgó una narrativa legitimadora y una interpretación jurídica desafiante de la visión predominante que permitió al país, aunque no siempre sin fricciones, ajustar la iniciativa a uno de sus grandes lineamientos de política exterior: el respeto al derecho internacional. Y, al mismo tiempo, permitió la generación de un relato unificador para todos los voceros nacionales. La coordinación de las distintas agencias que en una primera instancia tenían estrategias preferidas 
divergentes también resultó clave. A esto se debe incorporar una paciente diplomacia que dialogó constantemente con todos los actores preocupados por la reforma. En esto se destacan las reuniones con la JIFE, la burocracia internacional sin dudas más resistente al cambio, pero también los contactos con los representantes de otros Estados nacionales. El caso de Brasil y sus preocupaciones por posibles consecuencias de seguridad y de turismo cannábico ilustran este punto.

La alianza con la sociedad civil nacional — base de apoyo de la reforma-, y también con la sociedad civil y los expertos internacionales, capaces de influir en los gobiernos y en las opiniones públicas de sus países, debe resaltarse, así como entenderse desde la lógica del juego de dos niveles. Finalmente, el paso proactivo en la promoción de alternativas, mediante la construcción de alianzas regionales e incluso internacionales —evitando las incursiones unilaterales- contribuyó no solo a evitar los costos asociados a la reforma, sino también a contribuir a una proyección positiva de la imagen internacional del país.

En resumen, la estrategia uruguaya de presentación y defensa de su política de cannabis puede considerarse exitosa desde dos perspectivas: 1) aseguró un espacio de autonomía suficiente para continuar con la iniciativa doméstica sin dañar la imagen y reputación internacional del país; 2) logró la articulación de posturas comunes con otros miembros del orden internacional que, sin la intención de replicar el modelo uruguayo, coincidían en la necesidad de explorar alternativas frente al percibido fracaso del modelo actual. Este resultado, como se ha expuesto, se debe a una combinación de factores exógenos y endógenos. Puesto de otro modo, la ventana de oportunidad abierta por la postura permisiva de Estados Unidos y una región dispuesta a avalar cambios en el statu quo fue una condición externa necesaria; sin ella, todo intento nacional habría fracasado. No obstante, al mismo tiempo, la capacidad del gobierno de capitalizar la oportunidad a través de la articulación de una narrativa homogénea orientada a la legitimación y construcción de alianzas —incluso sin una planificación ex ante adecuada y sin un consenso previo al interior de los actores de gobierno-, es la otra condición necesaria que explica el resultado. Tan es así que, de hecho, la dimensión externa, que al día de hoy es 
considerada más un activo que un lastre, contrasta con las dificultades internas que aún previenen la completa implementación de la política.

\section{Reflexiones finales: implicanciones para el régimen internacional de combate a las drogas}

¿Qué significan las innovaciones introducidas por Uruguay para el régimen internacional de combate a las drogas? Como han señalado varios teóricos de las relaciones internacionales, representantes de distintas tradiciones en la disciplina, la importancia de los comportamientos socialmente aceptados, esto es, las normas informales que delimitan y por lo tanto restringen el rango de acciones concebidas como posibles por parte de los Estados, no deben ser subestimados (Carr, 1946; Hall, 1989; Wendt, 1999; entre otros). Está claro que un pequeño país como Uruguay, con su nueva política hacia el cannabis, no pretende ni puede aspirar a conseguir un cambio radical en el régimen imperante. Sin embargo, una iniciativa como la uruguaya genera un cuestionamiento de las creencias previamente establecidas, poniendo en tela de juicio los marcos normativos y cognitivos que la sustentan.

La noción de experimento que rodea al proyecto uruguayo, y su explícito objetivo de procurar avances en materia de salud y derechos humanos, permiten por lo tanto acomodar la iniciativa de una manera previamente no concebida, ampliando así el margen de lo posible. Y, a la vez, desde un punto de vista más práctico, en términos de política diplomática, tiene como consecuencia la reducción de los costos percibidos por otros Estados respecto a la innovación en sus propias fronteras, como documenta el análisis en profundidad presentado en este estudio. Solo así se entiende la avalancha de propuestas en la región latinoamericana tras la aprobación de la ley en Uruguay, con el caso extremo del presidente mexicano quien señaló explícitamente este punto ${ }^{6}$. De igual forma, antecedentes como

\footnotetext{
6 Aunque es preciso matizar que la efectiva implementación de políticas inspiradas en nuevos enfoques no ha seguido el ritmo evidenciado en el plano discursivo, sino que más bien, por el contrario, el statu quo ha prevalecido.
} 
los del modelo neerlandés de tolerancia demuestran que, más allá de las críticas recibidas por parte de los actores del régimen (Garat, 2013), el éxito de la política en el plano internacional reside en no denunciar los tratados internacionales sobre drogas que sirven como base para la normativa doméstica y al mismo tiempo pueden ser dejados en suspenso para el caso concreto de la marihuana (Barriuso, 2005).

El ensanchamiento del plano de lo posible y, especialmente, de lo aceptable, se observa igualmente en los documentos elaborados de cara a UNGASS 2016, en donde no solo varios países latinoamericanos y organizaciones regionales, sino actores sistémicos de especial relevancia como Estados Unidos y la Unión Europea incorporan el principio de flexibilidad y abren la puerta a potenciales reformas basadas en la evidencia. Continuar analizando la emergencia de nuevos cambios a nivel de los Estados nacionales, así como rastrear los cambios y las continuidades en la conceptualización de las políticas de drogas, nos permitirá concluir de forma más segura si el caso uruguayo es tan solo un outlier, o si estamos por el contrario en camino hacia un conjunto de mayores y más profundas transformaciones en la política internacional de drogas en los próximos años.

\section{Referencias}

Allison, G. (1971). Essence of Decision: Explaining the Cuban Missile Crisis. Boston: Little, Brown and Company.

Barriuso, M. (2005). Propuesta de modelo legal para el cannabis en el estado español. EGUZKILORE, (19), 151-167.

Boidi, M., Cruz, J. M. \& Queirolo, R. (2015). Rethinking the Leaf? Support for Marijuana Legalization in Uruguay, the United States and El Salvador, Paper to be presented at the 9th Conference of the International Society for the Study of Drug Policy (ISSDP) Ghent, Belgium, May 19-22.

Carr, E. (1946). The Twenty Years' Crisis 1919-1939: An Introduction to the Study of International Relations. [2 ed.] Londres: Macmillan.

Comini, N. \& Tokatlián, J. (2016). Guerra contra las drogas: ¿Se puede modificar el paradigma internacional? América Latina en UNGASS 
2016: un impulso restringido, una cumbre anodina. Notes Internacionals (CIDOB), (149).

Garat, G. (2013). Un siglo de políticas de drogas en Uruguay. Montevideo: Fundación Friedrich Ebert.

George, A. (1991). La decisión presidencial en politica exterior. Buenos Aires: GEL.

Gilpin, R. (1987). The Political Economy of International Relations. Princeton: Princeton University Press.

Hall, P. (1989). The Political Power of Economic Ideas: Keynesianism across Nations. Princeton: Princeton University Press.

Hernández Nilson, D., Pose, N. \& Raggio, A. (2016). Entre el norte y el sur. La política exterior de los gobiernos del Frente Amplio (2005-2014). Cadernos do Tempo Presente, (23), 38-53.

Hettne, B. \& Fredrik S. (2000). Theorising the Rise of Regionness. New Political Economy, 5 (3), 457-473.

Insulza, J. (2012). Escenarios para el problema de drogas en las Américas 2013-2025. Organización de Estados Americanos (OEA). Recuperado de http://www.up.ac.pa/ftp/2010/ob_droga/documentos/ escenario.pdf

Jelsma, M. (2016). UNGASS 2016: perspectivas para la reforma de los tratados y la coherencia de todo el sistema de la ONU en materia de políticas de drogas" Center for 21st Century Security and Intelligence Latin America Initiative.

Keohane, R. (1982). The Demand for International Regimes. International Organization, 36, (2), 325-355.

Kindleberger, C. (1981). Dominance and Leadership in the International Economy. International Studies Quarterly, 25, (83).

Krasner, S. (1982a). Structural Causes and Regime Consequences: Regimes as Intervening Variables. International Organization, 36, (2), 185-205.

Krasner, S. (1982b). Regimes and the Limits of Realism: Regimes as Autonomous Variables. International Organization, 36, (2), 497-510.

López, C. (2013). La política exterior en el gobierno de Mujica (2010- 2013). En Caetano, G. y otros (Eds.). Política en tiempos de Mujica III. A un año de las elecciones nacionales. Informe de Coyuntura No. 12, Estuario, Montevideo, pp. 69-82.

Magnus, L. (2015). La guerra contra las drogas: de Richard Nixon a Barack Obama. Nueva Sociedad (255) enero-febrero, 69-80. 
Moravsik, A. (1997). Taking Preferences Seriously: A Liberal Theory of International Politics. International Organization, 51, (4), 513-553.

Moravsik, A. (2008). The New Liberalism en Reus-Smith, C. and Snidal, D. (eds.). The Oxford Handbook of International Relations. Oxford: Oxford University Press.

Putnam, R. (1988). Diplomacy and Domestic Politics: The Logic of TwoLevel Games. International Organization, 42, (3), 427-460.

Peters, G. (1999). La politica de la burocracia. México: Fondo de Cultura Económica.

Sanahuja, J. (2012). Regionalismo post-liberal y multilateralismo en Sudamérica: El caso de UNASUR en Serbín, A., et al. (Coords.). El regionalismo "post-liberal" en América Latina y el Caribe: Nuevos actores, nuevos temas, nuevos desafíos (pp. 19-72). Buenos Aires: CRIES.

Serbín, A. (2012). Déficit democrático y participación ciudadana en el marco del regionalismo post-liberal en Serbín, A., et al. (Coords.). El regionalismo "post-liberal" en América Latina y el Caribe: Nuevos actores, nuevos temas, nuevos desafios (pp. 73-128). Buenos Aires: CRIES, pp. 73-128.

Stein, A. (1982). Coordination and Collaboration: Regimes in an Anarchic World. International Organization, 36, (2), 299-324.

Wendt, A. (1999). Social Theory of International Politics. Cambridge: Cambridge University Press.

\section{Notas de prensa (orden cronológico)}

(17 de septiembre de 2013). Como Uruguay no hay. Debate en Washington destacó iniciativa reguladora del mercado de la marihuana en La Diaria. Recuperado de http:/ /www.infodrogas.gub.uy/prensa/20130917/20130917_dia_001.htm\#noticia1

(24 de octubre de 2013). WOLA destaca actitud pionera y progresista de Uruguay en materia de políticas sociales Distinción a Milton Romani en Portal Presidencia Uruguay. Recuperado de https://www.presidencia. gub.uy/comunicacion/comunicaci onnoticias/hom enaje-romani-wola (20 de noviembre de 2013). Oficina de ONU pide al gobierno frenar votación de la marihuana en El País. Recuperado de http:/ / www.elpais. com.uy/informacion/onu-pide-frenar-ley-marihuan a.html 
(9 de diciembre de 2013). Bordaberry: Uruguay no es un laboratorio en Montevideo Portal. Recuperado de http:/ / www.montevideo.com.uy/contenido/Bordaberry-Uruguay-no-es-laboratorio-220856?plantilla=1149

(12 de diciembre de 2013). La ONU criticó la legalización de la marihuana en Uruguay en La Nación. Recuperado de http:/ /www.lanacion.com. ar/1646831-la-onu-critico-la-legalizacion-de-la-marihuana-en-uruguay

(13 de diciembre de 2013). Sacale color. Mujica a Estados Unidos por legalización de la marihuana: se hizo mucha bulla en La Diaria. Recuperado de http:/ / www.infodrog as.gub.uy/prensa/20131213_16/20131213_di_001.htm

(23 de marzo de 2014). A instancias de Uruguay, la ONU revisará en 2016 política de drogas en La República. Recuperado de http:/ / www.republica.com.uy/a-instancias-de-uruguay-la-onu-revisara-en-2016-politica-de-drogas/442528/

(26 de abril de 2014). Gobierno mostró a diplomáticos ley de regulación de cannabis y ratificó que Uruguay cumple en Portal Presidencia Uruguay. Recuperado de https://www.presidencia.gub.uy/comunicacion/comunicacionnoticias/cancilleria-ley-marihuana-canepa-porto-calzada

(7 de mayo de 2014). Mujica sobre marihuana: Los retrógrados se van a asustar en BBC. Recuperado de http://www.bbc.com/mundo/noticias/2014/05/140506_uruguay_entrevista_jose_mujica_jgc

(9 de mayo de 2014). Marihuana. Oficina antidrogas de ONU: se podrá aprender mucho de Uruguay en ElEspectador. Recuperado de http:// www.inf odrogas.gub.uy/prensa/20140508/20140509_esp_001.htm

(9 de mayo de 2014). Uruguay: ¿marihuana sin impuestos? en $A B C$. Recuperado de http:/ / www.infodrogas.gub.uy/prensa/20140508/20140509_ ab_001.htm

(20 de mayo de 2014). Gobierno de Uruguay reafirma política de abordaje integral en problemática de drogas Calzada en reunión ministerial de CELAC en Portal Presidencia Uruguay. Recuperado de https://www. presidencia.gub.uy/comunicacion/comunica cionnoticias/calzadatemas-conferencia-drogas

(23 de mayo de 2014). Uruguay has Big Hope for Pot Industry en The Wall Street Journal. Recuperado de: http://www.wsj.com/articles/uruguayhas-high-hopes-for-pot-industry-1400877635

(27 de mayo de 2014). La UE sigue de cerca el proceso de legalización de la marihuana en Uruguay en BBC. Recuperado de http:/ /www.infodrogas.gu b.uy/prensa/20140527/20140527_bb_001.htm 
(22 de junio de 2014). Químicos lanzan campaña para no vender marihuana en las farmacias en El País. Recuperado de http://www.elpais.com. uy/informacion/quimicos-lanzan-campana-no-vender.html

(2 de julio de 2014). Alertan riesgos en la región por la ley de marihuana en Uruguay en El País. Recuperado de http://www.elpais.com.uy/ informacion/alertan-riesgos-region-ley-marihuana.html

(21 de julio de 2014). Argentina discute marihuana. Pepe ve, porro quiere en Montevideo Portal. Recuperado de http://www.montevideo.com. uy/contenido/Argentina-discute-marihuana-240538?plantilla=1391

(1 de agosto de 2014). La marihuana quizás nunca llegue a las farmacias en El Nuevo Herald. Recuperado de http://www.infodrogas.gub.uy/ prensa/20140801/20 140801_NH_001.htm

(1 de agosto de 2014). La marihuana quizás nunca llegue a las farmacias uruguayas en Infobae. Recuperado de http://www.infobae.com/2014/08/01/ 1584780-la-marihuana-quizas-nunca-llegue-las-farmacias-uruguayas /

(15 de agosto de 2014). Julio Calzada participó en congreso sobre drogas en Colombia. Los unos y los otros en Montevideo Portal. Recuperado de http://www.montevideo.com.uy/contenido/Julio-Calzada-participoen-congreso-sobre-drogas-en-Colombia-242796?plantilla $=1391$

(26 de agosto de 2014). Marihuana: los líderes de la región desafían el tabú de la legalización en ElComercio. Recuperado de http:/ /www.infodrogas.gub.uy/prensa/2014 0822/20140826_COM_001.htm

(22 de octubre de 2014). Analizan utilizar modelo uruguayo de regulación de la marihuana en Última Hora. Recuperado de http://www. ultimahora.com/analizan-utilizar-modelo-uruguayo-regulacion-lamarihuana-n840589.html

(11 de marzo de 2015). Uruguay y su política de drogas en La República. Recuperado de http:/ / www.republica.com.uy/su-politica-de-drogas/505605/

(11 de marzo de 2015). Este año se venderá marihuana en farmacias. Política de Uruguay sobre marihuana se ve con mucho respeto en la ONU en La República. Recuperado de http://www.republica.com. uy/marihuana-en-farmacias/505649/

(12 de marzo de 2015). Juntos con EE.UU en la experiencia de la marihuana en Portal 180. Recuperado de http:/ /www.180.com.uy/articulo/54084_ uruguay-y-estados-unidos-juntos-en-la-experiencia-de-la-marihuana (12 de abril de 2015). Uruguay impulsa diálogo abierto sobre drogas en Asamblea de Naciones Unidas en 2016 Resolución del Consejo de 
DD. HH en Portal Presidencia Uruguay. Recuperado de https://www. presidencia.gub.uy/comunicacion/comunicacionnoticias/romanidrogas-resolucion-consejo-derechos-jumanos

(24 de abril de 2015). La ONU invita a Uruguay a un debate de alto nivel contra las drogas Hablemos en Montevideo Portal. Recuperado de http://www .montevideo.com.uy/contenido/La-ONU-invita-aUruguay-a-un-debate-de-alto-nivel-contra-las-drogas-268993

(26 de junio de 2015). Uruguay se planta otra vez ante Naciones Unidas por marihuana. El gobierno defiende ante la ONU su política de reducción de riesgos en ElPaís. Recuperado de http:/ / www.elpais.com. uy/informacion/uruguay-se-planta-onu-marihuana.html

(15 de diciembre de 2015). Es lo que tienen las drogas en Montevideo Portal. Recuperado de http://www.montevideo.com.uy/contenido/Romanidice-que-convenciones-de-ONU-sobre-drogas-tienen-debilidades-eincoherencias--293717?plantilla $=1149$

(21 de diciembre de 2015). Cabezas criollas. Uruguay se prepara para debate de Naciones Unidas sobre políticas de drogas en La Diaria. Recuperado de http://www.infodrogas.gub.uy/index.php?option=com_content $\&$ view $=$ article $\& i d=2984 \&$ catid $=38 \&$ Itemid $=82 \#$ noticia 1

(4 de febrero de 2016). EEUU respaldó política de drogas de Uruguay y su ley de marihuana Búsqueda. Recuperado de http:/ /www.busqueda.com.uy/nota/eeuu-respaldo-politica-de-drogas-de-uruguay-y-su-ley-de-marihuana 